\title{
JOGANDO BOLICHE NO BRONX: os interstícios incivis entre a sociedade civil e a sociedade política*
}

\section{Laurence Whitehead}

\section{Introdução}

O que compreendemos pelo termo "sociedade civil"? Como ela surge? Como se relaciona com o pluralismo, a democracia e a democratização? Se existe uma tendência à sua desintegração ou autodestruição, isso põe em risco a consolidação dos regimes democráticos, ou torna apenas mais exacerbadas as angústias sobre a qualidade de nossas democracias "realmente existentes" (poliarquias)? Se ela desenvolve uma capacidade de autopreservação, esta reforça obrigatoriamente 0 aprofundamento da democracia política, ou esse processo pode ocorrer às custas do universalismo e da não discriminação necessárias para a autêntica democracia?

A contribuição do artigo está em oferecer uma abordagem muito ampla - e provisória dessas questões. $O$ seu ponto de partida é a discrepância entre nossa visão inclusiva de cidadania e nossa visão tacitamente mais restritiva das características da sociedade civil.

0 constitucionalismo liberal moderno estende 0 âmbito da cidadania (os direitos políticos formais) a virtualmente todos os adultos em uma certa jurisdição territorial. Em um mundo de Esta- dos territoriais, as exceções a essa regra são definidas de forma precisa e delimitadas cuidadosamente (por exemplo, os presos, os comprovadamente insanos e mentalmente incapazes, os refugiados e os asilados políticos). Se ocorresse de outra forma e as categorias de exceção fossem definidas frouxamente ou fossem facilmente extensíveis, então amplos segmentos da comunidade política poderiam sentir seus direitos de cidadania potencialmente em risco e, em conseqüência, poderiam se mobilizar para defender direitos políticos mais amplos. Apesar de tudo, a concepção de direitos de cidadania quase universal e inclusiva, vigente atualmente, somente foi alcançada historicamente através da pressão e da agitação por e em benefício daqueles que eram inicialmente excluídos e marginalizados da comunidade política territorial. 0 resultado é que, nos dias da hoje, a esmagadora maioria das comunidades políticas representativas

* Texto publicado originalmente, com o título "Bowling in the Bronx: the uncivil interstices between civil and political society", no livro Civil society: democratic perspectives, organizado por Robert Fine e Shirin Rai (Frank Cass, 1997).

Tradução de Eduardo Cesar Marques. 
é fortemente orientada para a universalidade. Em outras palavras, elas contêm um forte pressuposto a favor da manutenção dos direitos de cidadania. Isso é verdadeiro tanto para as democracias estabelecidas há bastante tempo (poliarquias), como para os muitos regimes constitucional e potencialmente democráticos frágeis e estabelecidos em período recente (democracias recentes).

Entretanto, embora a cidadania moderna possa assumir a aparência de universalidade, o mesmo não se pode dizer com relação ao pertencimento à "sociedade civil". Esse é o ponto de vista defendido por este artigo. A distinção entre uma concepção inclusiva de cidadania (e conseqüentemente de "sociedade política") e uma visão mais seletiva e restritiva do que constitui a sociedade civil dependerá, é claro, de como a segunda categoria é definida. Nossa discussão, como conseqüência, inicia-se por uma rápida revisão das possíveis definições concorrentes, todas implicando graus maiores ou menores de restrição que a cidadania universal. Em outras palavras, todas as definições admitem a existência de um terceiro conjunto de "cidadãos incivis", ou pessoas que têm direitos políticos mas não se submetem aos constrangimentos impostos pela "sociedade civil". Como aparentemente não há um único sentido consensual na definição de nossa segunda categoria, existem visões alternativas das formas assumidas por tais constrangimentos; mas qualquer que seja a forma adotada, uma certa parcela de "civilidade" deve necessariamente estar incluída. 0 estudo, conseqüentemente, propõe uma definição de trabalho para a categoria que incorpora esse requisito. 0 presente trabalho avança então para considerar as implicações da incivilidade, tanto para nossa compreensão da "sociedade civil" como para nossas teorizações sobre a relação entre a sociedade civil e a democratização.

A premissa subjacente é a de que, seja ou não adotada essa definição, haverá necessariamente uma distância substancial entre as concepções mais universalistas de sociedade política modema e noções mais restritivas e exatas de sociedade civil. Os interstícios entre essas duas formas sociais irão favorecer a produção de múltiplas variantes de "incivilidade" (uma categoria residual derivada da noção de sociedade civil que pode, conseqüentemente, ser desagregada e desconstruída). A discussão concluiu que a qualidade e a estabilidade tanto das democracias recentemente constituídas como das próprias "poliarquias" consolidadas são provavelmente afetadas pela solidez e pela estrutura da sociedade civil, e que essas características, pelo seu lado, são fortemente condicionadas pela natureza e pela força dos desafios que possam surgir dos "interstícios incivis".

A fraqueza da sociedade civil e os riscos colocados pelas várias formas de "incivilidade" são particularmente evidentes em muitas democracias recentemente construídas. Tanto nas experiências pós-autoritárias como nas pós-comunistas, os esforços de democratização são freqüentemente obscurecidos pela emergência ou a proliferação de formas anti-sociais de individualismo e organização de grupos que substituem, ou até procuram subverter, as formas de associação civil celebradas pelos teóricos da "sociedade civil". Uma descrição reconhecida internacionalmente para tal florescimento de incivilidade pode ser encontrada no termo "máfia". Se essa fosse uma questão simples e direta de criminalidade seria de relevância limitada para os estudiosos da política, embora possa ser difícil de ser solucionada pela polícia. Entretanto, ela torna-se uma preocupação central quando os requisitos de democratização incluem a extensão dos direitos políticos e de cidadania para amplos setores da população que não apenas podem não ter experiência prévia de política democrática, mas também têm parcos recursos para escapar das redes de cooptação e controle políticos do tipo "máfia". Ela também é uma preocupação central nos casos em que as formas incivis de associação são deixadas como herança do ancien régime, ou surgem no curso da luta política entre grupos que não são leais à ordem constitucional prevalecente, caso essa seja frágil. Os incentivos para organizar formas intolerantes e incivis de associativismo são particularmente fortes onde as reivindicações de privilégios e propriedade são contestáveis politicamente, onde os colaboradores do regime anterior ainda seguem impunes por atividades criminosas e temem ações "revanchistas", e onde 0 
sistema judicial parece incapaz de sustentar um domínio legal amplo e imparcial. Essas são, é claro, condições características de muitas democracias constituídas recentemente.

Entretanto, a discussão não se direciona somente, ou mesmo principalmente, para os esforços de muitas sociedades que tentam consolidar suas frágeis democracias recentes. As poliarquias estabelecidas há muito tempo nos países da Organização para Cooperação Econômica e Desenvolvimento (OCDE) também manifestam bruscas disjunções entre o escopo de suas sociedades civis e políticas. A Itália, terra de origem da máfia, recentemente experimentou 0 potencial de desestabilização macropolítica dos interstícios incivis de uma forma particularmente dramática. ${ }^{1}$ Mas essa incivilidade adota diversas formas e aparece em muitas poliarquias. A disseminação da violência de rua nos banlieux de quase todos os grandes centros, por exemplo, tem-se tomado uma das questão mais sensíveis na França, particularmente nos locais onde o desemprego jovem e as tradições islâmicas coincidem. A polícia francesa agora mantém registros mensais dos incidentes enfrentados em 1.017 quartiers que foram classificados como "sensitifs". O mês de julho de 1995 apresentou um recorde com 955 desses incidentes, sendo que a média está em torno de 500. ${ }^{2}$ A Inglaterra ${ }^{3}$ também não é uma exceção, nem mesmo os Estados Unidos, particularmente em algumas áreas obsoletas dos centros das cidades.

$\mathrm{Na}$ verdade, o título deste artigo foi escolhido para destacar a fraqueza do associativismo civil em partes dos Estados Unidos de uma forma não prevista por Tocqueville. ${ }^{4}$ O Bronx foi apontado na esperança de se evitar o exotismo que se originaria se situássemos nossas discussões da sociedade civil no contexto de localizações tão ideal-típicas do Terceiro Mundo como El Alto (La Paz), a Baixada Fluminense (Rio de Janeiro), ou Guguletu (Cidade do Cabo). A premissa, aqui, é que uma vez que tenhamos jogado boliche no Bronx, teremos avançado boa parte do caminho para compreender também a relação entre sociedade civil e democracia na Bolívia, no Brasil e na África do Sul.

\section{Os vários significados de "sociedade civil"}

Q uando Hobbes (1651, parte 2, cap. 5, parag. 9) se referiu à "sociedade civil", ele igualava o termo a "cidade" ou "união". O conceito era diferenciado da noção de "multiplicidade" pela premissa de que os indivíduos respectivos se tinham inserido em alguma forma de acordo ou contrato através do qual eles concordavam em subordinar suas vontades individuais a uma vontade unificada coletiva, se não por outra razão, apenas para a manutenção da paz e para a defesa comum. Mas Hobbes não acreditava que a criação de uma sociedade civil poderia em algum momento abolir os medos e perigos subjacentes ao que ele denominava de o "estado de natureza". Embora a sociedade civil pudesse suspender a ação de tais perigos, o processo da vida política seria sempre reversível. A liberdade e a interação social tornadas possíveis pela sociedade civil estariam permanentemente em risco pela possibilidade de regressão para uma comunidade não social. Na verdade, o medo de tal regressão era provavelmente 0 incentivo necessário para sustentar 0 constructo artificial representado pela sociedade civil.

Diferentemente, a versão de Hegel da "sociedade civil" era derivada não do medo humano da morte, mas de suas necessidades materiais articuladas pela divisão do trabalho. Nem a família, nem a associação religiosa ou política pertenciam a esse domínio, restrito ao campo da racionalidade instrumental e individualista. Entretanto, tanto Hobbes quanto Hegel viam um antagonismo radical entre sociedade civil e criminalidade sem lei. Os indivíduos na sociedade civil (que para Hegel era estruturada solidamente por guildas, corporações e comunidade - todas formas de associação compulsórias e não voluntárias) perseguiriam seu autointeresse dentro do quadro geral de direitos e obrigações mutuamente reconhecidos regulado pela autoridade pública. Essa noção de sociedade civil implicava um sistema judicial confiável e imparcial.

Hegel, seguindo os economistas políticos escoceses, também estava preocupado com as 
propriedades autodestrutivas de uma sociedade civil não constrangida por nenhum princípio normativo mais amplo. Segundo essa visão, o desenvolvimento não controlado da divisão de trabalho poderia gerar uma parte da sociedade que fosse tanto material como espiritualmente empobrecida pela monotonia e estreiteza da sua ação. Esse setor tenderia a perder 0 auto-respeito e, em conseqüência, a sua identificação com a comunidade como um todo: "torna-se evidente, portanto, que apesar do excesso de riqueza, a sociedade civil não é rica suficientemente, isso é, seus próprios recursos são insuficientes para limitar a pobreza excessiva e a criação da turba miserável" (Hegel, 1942, parag. 245). Apenas a incorporação da sociedade civil em uma comunidade mais ampla (para Hegel, a comunidade política) poderia conter 0 seu potencial autodestrutivo. Mas é claro que nem Hegel, nem Hobbes estavam sugerindo que a autoridade política necessária para regular a sociedade civil deveria ser democrática.

Marx preservou o arcabouço da teoria hegeliana, embora invertendo o seu mecanismo. $\mathrm{Na}$ forma mais completa dessa versão, a divisão do trabalho e a sociedade civil "burguesa" daí resultante tornaram-se os motores da mudança social, enquanto os domínios político, ideológico e normativo tornaram-se meras conseqüências, a ela subordinados. Além disso, as características autodissolutivas da sociedade civil deram origem a uma teoria dialética do progresso revolucionário, através do qual a sua forma burguesa seria inevitavelmente substituída por uma versão socialista mais avançada. A relação conseqüente entre sociedade civil e democracia política era, portanto, de antagonismo. A democracia "real" teria de esperar pela revolução socialista. A burguesia, em sua fase progressista, poderia temporariamente se fazer acompanhar de democracia formal (como uma arma contra as classes pré-burguesas), mas o seu compromisso político epifenomênico estaria atado ao destino, já que a classe operária cresceria em força e autoconsciência e desafiaria a supremacia política da classe capitalista. $\mathrm{Na}$ versão marxista, portanto, não poderia haver a premissa de congruência inerente e supra-história entre a sociedade civil e a administração da justiça, nem tampouco de antagonismo óbvio entre a burguesia e as classes criminosas.

Tocqueville foi, provavelmente, o primeiro teórico de importância a apresentar a sociedade civil como uma contrapartida indispensável para uma democracia estável e vigorosa, ao invés de uma alternativa a ela. Mas as associações voluntárias que constituíam o cerne da sua noção de "sociedade civil" eram muito distintas dos pactos considerados por Hobbes, das corporação de ofício levadas em conta por Hegel ou da classe burguesa de Marx. Na verdade, se a busca do autointeresse material era 0 que distinguia a sociedade civil no pensamento dos dois teóricos alemães, 0 que inspirou o liberal francês foi a contenção desse materialismo nos limites das instituições voluntárias benevolentes (que podiam ser vistas como extensões da família, ou como aplicações práticas da fé religiosa). Ao contrário de uma parte da literatura neotoquevilliana dos dias de hoje, 0 Tocqueville original não era nem pré-político (as instituições do governo local figuravam de forma destacada em sua descrição das bases da democracia norte-americana), nem sentimental (seus escritos contra o conformismo social e intelectual nas pequenas cidades da Nova Inglaterra contrastam de maneira marcada com as nostalgias tão em moda no período).

De acordo com a sua descrição, o que era fundamental nas instituições políticas norte-americanas era a profusão de suas associações políticas democráticas. Elas é que levariam os indivíduos isolados a cooperar para propósitos coletivos apesar da ausência de uma aristocracia e da grande distância do nível federal do Estado. Nessa concepção de sociedade civil - "associações que são formadas na vida social sem referência a objetos políticos" - , as atividades comerciais, educacionais e religiosas são todas incluídas. $\mathrm{Na}$ verdade, além da divisão do trabalho, Tocqueville (1945, vol. II, cap. 5, parag. 2) refere-se a "associações de mil outros tipos: religiosas, morais, sérias, fúteis, gerais ou restritas, enormes ou diminutas; para produzir diversão, para criar seminários, para construir hospedarias, para edificar igrejas, para difundir livros e para mandar missionários para a Austrália e a Nova Zelândia". 
E acrescenta (talvez em benefício de Foucault): "dessa forma eles fundaram hospitais, prisões e escolas". Essa é a razão da angst de Putnam com o declínio do boliche como atividade recreativa, o que para ele reflete uma crise profunda na democracia norte-americana contemporânea. Enquanto a sociedade civil de Hobbes deve fazer frente aos riscos do estado de natureza, e para Hegel ela reflete 0 crescimento do comércio como esfera supostamente independente da política, para Tocqueville ela preenche 0 vácuo deixado pela ausência de uma aristocracia. Portanto, pela primeira vez, na concepção de Tocqueville, a sociedade civil e a democracia são vistas como inerentemente relacionadas entre si - para os autores anteriores elas eram princípios da organização social desconectados e na verdade potencialmente antagônicos.

Cada uma dessas caracterizações sucessivas da sociedade civil foi construída a partir de uma realidade social muito distinta e específica, e conseqüentemente propunha a inclusão (ou exclusão) de diferentes entidades corporativas ou coletivas. Para Hegel, a religião era própria do mais alto domínio da ação estatal, enquanto para Tocqueville esse lugar era preenchido pela expressão voluntária da auto-organização local. Para Marx, a associação dos trabalhadores nos sindicatos era uma realidade fundamental, ao passo que para Tocqueville era o jornal local que produzia a agregação dos colonos norte-americanos até então dispersos. Essas diferenças de ênfase e concepção refletem não apenas pontos de referência sociológicos contrastantes, mas também posições teóricas diferentes com respeito às bases da organização estatal e às fontes da ação coletiva.

Desde a metade do século XIX, é claro, as teorias da sociedade civil de que dispomos foram muito elaboradas e posteriormente diversificadas, mas o esforço de seguir os passos desses desenvolvimentos ultrapassaria os propósitos deste artigo. ${ }^{5}$ É suficiente dizer que continuamos sem uma compreensão única, unificada e consensual do termo. Até hoje, a maioria do autores que escreve sobre a "sociedade civil" deixa dúvidas sobre se os sindicatos ocupam um lugar central ou marginal nas suas concepções; se a mídia deve ser vista como interna ou externa; se o papel neutro do Estado de direito é uma precondição ou apenas um ideal utópico que os ativistas da sociedade civil deveriam usar para criticar os registros existentes da manipulação política; e, por fim, se a democracia política brota de, coexiste com, ou ameaça poluir os densos princípios associativos da sociedade civil.

Depois de apresentar essas dúvidas sobre os vários sentidos do termo, devemos, para poder prosseguir, estabelecer uma definição de trabalho, mesmo que de forma arbitrária. A que se segue utiliza uma formulação recente proposta por Philippe Schmitter, que tem o mérito de ser depurada a partir de uma ampla variedade de realidades sociais contemporâneas (isso é, não generaliza de forma óbvia a partir de um ponto de vista etnocêntrico), e estrutura-se a partir da preocupação subjacente de Schmitter com as condições necessárias para a consolidação dos regimes democráticos modernos (tanto democracias antigas como novas). A sua definição de sociedade civil é a seguinte: "um conjunto ou sistema de grupos intermediários auto-organizados" que: (a) são relativamente independentes tanto das autoridades públicas quanto das unidades privadas de produção e reprodução, isso é, firmas e famílias; (b) são capazes de deliberar sobre e realizar ações coletivas na defesa/ promoção de seus interesses ou paixões; (c) não tentam substituir nem os agentes estatais nem os (re)produtores privados ou aceitar responsabilidades de governar a comunidade política como um todo; (d) não aceitam agir sob regras preestabelecidas de natureza "civil" ou legal.

Schmitter acrescenta que a "sociedade civil, conseqüentemente, não é uma propriedade simples, mas composta. Ela se apóia em quatro condições ou normas: (1) autonomia dual; (2) ação coletiva; (3) não usurpação; (4) civilidade" (Schmitter, 1995). ${ }^{6}$ Como a maior parte das definições, esta pode ser lida de inúmeras formas, mas parece excluir organizações do tipo da máfia (tanto em (3) como em (4)) e também os tipos de organizações mais "segmentárias" que tanto preocuparam Gellner, por serem, na sua opinião, opressoras do individualismo. ${ }^{7}$ A interpretação de Gellner também se baseia nas quatro condições ou normas 
listadas. É possível sustentar que estas pressupõem, coletivamente, uma forma "modema" e/ ou "individualista" de organização social.

Correndo o risco de sobrecarregar 0 texto com definições, devemos acrescentar algo ao termo-chave "civilidade" para dar conteúdo à quarta norma de Schmitter. A definição de Collingwood introduz uma dimensão mais familiar de civilidade, baseada no comportamento interpessoal, para além de qualquer compromisso de agir de acordo com os constrangimentos de regras legais preestabelecidas:

Comportar-se com civilidade com relação a alguém significa respeitar os seus sentimentos, abster-se de aborrecê-lo, amedrontá-lo, ou (brevemente) fazer surgir nele alguma paixão ou desejo que possa diminuir seu auto-respeito, isso é, amedrontar a sua consciência de liberdade fazendo-0 sentir que a sua liberdade de escolha está em risco de desmoronar e a sua paixão ou desejo está em vias de assumir o controle. ${ }^{8}$

Isso pode ser considerado um aspecto essencial da civilidade não coberto pela conformidade mínima às regras acordadas anteriormente. De outra forma, "obedecer ao texto e não ao espírito" de um acordo pode ser considerado um comportamento "civil", assim como a obediência a acordos incivis.

\section{A ausência de congruência entre sociedade "civil" e sociedade "política"}

Todos os significados distintos discutidos acima, e certamente também a definição de trabalho selecionada ao final, apontam para formas de organizações associativas voluntárias (ou ao menos não reprimidas) que provavelmente não se distribuem de maneira uniforme nos terrenos geográficos e sociais cobertos pelos Estados territoriais modernos (as comunidades políticas). A ocorrência de desenvolvimento desigual é mais ou menos auto-evidente no domínio da divisão do trabalho. É também uma característica virtualmente inescapável tanto nas corporações profissionais de Hegel quanto nas associações locais coordenadas em torno de jomais de Tocqueville. O mesmo é verdadeiro se observarmos as coletividades apoiadas pela Igreja como um componente crucial da sociedade civil: elas tendem a ser mais densamente concentradas em algumas áreas e em alguns estratos sociais do que em outros. De modo similar, os sindicatos de trabalhadores e as formas de organização comunitária tendem a ser geograficamente concentradas. Igualmente, se seguimos Parsons na ênfase da centralidade das instituições educacionais (especialmente universidades), novamente encontraremos uma cobertura social e espacial desigual. A definição de Schmitter carrega a mesma implicação, já que as quatro condições por ele especificadas são mais seguramente preenchidas em algumas situações sociais do que em outras (especialmente a "civilidade", mas também a autonomia dual etc.). Embora alguns desses padrões de distribuição possam se compensar (fortes associações da classe trabalhadora onde a cobertura de educação superior é fraca etc.), outros são cumulativos. Na verdade, todas essas definições parecem significar que a sociedade civil é mais densa em Hampstead do que em Brixton e em Santa Mônica do que em East Los Angeles. Qualquer que seja a maneira de especificar mais precisamente os componentes da sociedade civil, algumas partes da comunidade dos cidadãos serão atendidas em excesso com "vida associativa densa", enquanto outras terão falta de tais dimensões. (Isso é provavelmente verdadeiro até mesmo para a "mundoda-vida da interação comunicativa" de Habermas, embora seja difícil ter certeza a esse respeito. ${ }^{9}$ )

Não podemos nos apoiar nem no mercado, nem no Estado para equalizar essa distribuição social desigual do associativismo voluntário. Não se pode confiar a tarefa ao mercado porque este obedece à soberania do consumidor, que é distorcida em benefício dos possuidores de maiores rendas. Tampouco pode-se confiar no Estado, pois a assembléia soberana é também tipicamente distorcida em benefício dos grupos mais bem articulados e organizados na comunidade política (na verdade, não raramente 0 parlamentarismo é tanto elogiado como criticado por ser a forma de governo que melhor assegura a ascendência da socieda- 
de civil sobre a vontade republicana). Os teóricos do associativismo que querem preservar suas características voluntárias e participativas por conseqüência resistem à padronização imposta centralizadamente e vêem a regulação do Estado como uma ameaça à liberdade. ${ }^{10}$ Mas, nesse caso, que mecanismos podem contrabalançar esse processo e reduzir as desigualdades da sociedade civil? A esperança de que, sendo as associações voluntárias benéficas, aqueles que se ressentem da sua falta possam ser ensinados ou encorajados a criá-las parece-me um argumento frágil para contrabalançar a situação.

Como temos conhecimento a partir de inúmeros estudos sobre polícia e administração da justiça, mesmo aqueles direitos legais que são formalmente uniformes em toda a comunidade política são, na prática, distribuídos seletivamente de alguma forma. A pobreza, a raça, a origem familiar não privilegiada e daí em diante fornecem marcadores negativos virtualmente universais mesmo nos mais consolidados e "social-democráticos" dos Estados nacionais. Robert Putnam (1994) recentemente chamou a atenção para a evidência de variações locais e regionais fortes na qualidade da vida cívica em diferentes partes da Itália, e Francis Fukuyama (1995) esboçou um quadro para a realização de comparações similares em nível internacional. Na maior parte das democracias recentes, os principais atributos da sociedade civil tendem a ser altamente concentrados em pontos específicos, freqüentemente reservados a uma minoria da população, e com frequência têm origem em privilégios conferidos pela estrutura de poder pré-democrática. Logo, na medida em que o Estado de direito se constitui em um componente essencial da sociedade civil, criado e mantido publicamente, a justiça imparcial é tipicamente uma aspiração ao invés de uma conquista realizada em amplos campos do panorama social na maior parte das democracias "realmente existentes". (Como Cohen e Arato (1992, pp. 440-442) admitem de forma relutante, embora os "direitos fundamentais devam ser vistos como princípios organizadores de uma sociedade civil moderna, a sociedade civil em formação [...] [como recentemente no Leste Europeu] pode por um tempo ter que funcionar sem uma estrutura consolidada de direitos".)

A sociedade civil não apenas é distribuída de forma desigual no espaço social em um momento particular do tempo; ela também se desenvolve de forma desigual, e de acordo com uma lógica que é distinta daquela da formação do Estado ao longo do tempo. Obviamente, cada uma das diversas definições de sociedade civil apresentadas acima carrega em si uma teoria implícita distinta de causalidade histórica. Na verdade, 0 mais provável é que os processos que estiveram envolvidos na geração das tradições cívicas do norte da Itália tenham sido de alguma forma diferentes daqueles que produziram as pequenas cidades norte-americanas de Tocqueville, ou a sociedade civil emergente na Polônia pós-comunista. 0 que nos interessa aqui, entretanto, é a conclusão de que qualquer que tenha sido o caminho histórico seguido, os padrões resultantes de vida associativa e comunicação social serão altamente estruturados, com setores tradicionalmente mais favorecidos e centrais e outros marginais ou excluídos. Dependendo da localização de cada pessoa nessa estrutura de privilégios e oportunidades, e do grau de abertura e flexibilidade do sistema, é possível considerar a sociedade civil resultante tanto como a expressão mais autêntica e a garantia durável de uma democracia política, quanto como a mais flagrante negação da sua promessa universalista. ${ }^{11}$

Em contraste com os ritmos de desenvolvimento incrementais, desiguais e mesmo reversíveis que caracterizam o crescimento da sociedade civil, os regimes políticos modernos são freqüentemente constituídos, à primeira vista, como estruturas coerentes e interdependentes e que têm pretensões a uniformizar a cobertura dos direitos em suas jurisdições territoriais respectivas. Os novos Estados criados na Europa depois de 1918 ou na África e na Ásia depois de 1945 fornecem muitas ilustrações recentes dessa tese, mas ela se aplica também a muitas democracias recentes criadas com o colapso soviético em 1989-91. Em quase todos esses casos, as reivindicações de cobertura uniforme e de igualdade política formal para todos os cidadãos na sua jurisdição eram, inicialmente, não mais do que meras aspirações, ou ficções legais, para a 
maior parte da população. Não obstante, essas novas diretrizes políticas de cidadania territorial e igualdade entre os cidadãos foram criadas, em princípio, em um momento específico (por exemplo, através da elaboração de uma constituição), depois do que elas adquiriram universalidade instantânea. Nos casos que nos interessam aqui, um conjunto completo de direitos políticos democráticos foi ostensivamente conferido a um conjunto de cidadãos criados de uma hora para outra. Apesar disso, a criação repentina de sociedades políticas inclusivas inteiramente novas pode não coincidir com nenhum mapa de vida associativa densa preexistente. A questão óbvia é a seguinte: como as práticas associativas e comunicativas da "sociedade civil" se relacionam com as aspirações ou as ficções jurídicas da "sociedade política" nas novas democracias? Se existe mais de uma via histórica para 0 estabelecimento de uma sociedade civil, aparentemente pode existir mais de uma via para a que a sociedade civil se envolva na construção de um regime político democrático.

É evidente que pode existir um crescimento lento da sociedade civil que acabe finalmente por criar as condições para a implantação da democracia política. (Essa é a interpretação Whig para a história britânica, e também se aplica à visão dominante sobre a democratização da Espanha). Entretanto, uma seqüência inversa também poderia ocorrer, isto é, um regime político formal seria implantado primeiro, e somente em período subseqüente a sociedade civil - talvez criada e nutrida por um Estado liberal protetor - amadureceria gradualmente. (Isso poderia sugerir um modelo ocidental padrão para a teorização da democratização de muitos Estados pós-comunistas, e também poderia se aplicar à experiência dos "protetorados", como a democratização de Porto Rico e do Havaí.) Outras combinações são também possíveis em teoria - uma sociedade civil que atinja um alto nível de desenvolvimento sem nunca chegar a um regime político democrático (como Hong Kong, por exemplo), ou uma sociedade civil que se desenvolva tomando como base para a garantia de suas liberdades e direitos a exclusão dos não-membros da participação política (sejam eles tamils, palestinos, cipriotas turcos, muçulmanos ou "bantus"). Onde as novas fronteiras políticas são incongruentes com os antigos mapas de vida associativa, é igualmente provável que sociedades civis periféricas e estrangeiras sejam prejudicadas à medida que as sociedades civis centrais são fortalecidas. Se a situação é analisada desse ponto de vista comparativo amplo, aparentemente não há razões fortes - teóricas ou empíricas - para que se presuma a existência de uma única relação fortemente determinada entre a sociedade civil e a democracia política. Se as duas são facilmente separáveis, e em princípio incongruentes, precisamos examinar mais de perto os interstícios entre elas.

\section{"Sociedade incivil" e democracia política}

Nas situações sociais em que a sociedade civil é fraca ou ausente, aplica-se o inverso das quatro condições de Schmitter: (1) invasão da autonomia dual, (2) que subverte a capacidade de deliberação e pode encorajar (3) usurpação e (4) incivilidade. Essa formulação abstrata incorpora uma grande variedade de possibilidades mais específicas, já que ameaças à sociedade civil podem vir de muitas - e freqüentemente múltiplas - fontes, e podem ser motivadas por processos políticos, socioeconômicos, ou mesmo tecnológicos. ${ }^{12}$ Consideremos uma rápida lista de alguns dos mais celebrados exemplos históricos - a subversão da sociedade civil na República de Weimar pelo Partido Nazista, seguida pelo Partido Socialista Unitário na Alemanha Oriental após 1945; a máfia na Sicília republicana; 0 conformismo clerical católico na Irlanda rural; o islamismo fundamentalista nos bidonvilles de Maghreb; a conformidade imposta pelo Estado em Cingapura, e alguns acrescentariam a docilidade manipulada pela mídia dos Estados Unidos de Eisenhower, o nepotismo imoral das Filipinas ou a exclusão baseada em castas na Ásia do Sul. Essa lista não deve ser lida como a reunião de todos esses fenômenos diversos em uma amálgama indiferenciada de "ameaças à liberdade ocidental", nem tampouco deve-se aderir aos julgamentos sociais e históricos específicos de respon- 
sabilidade que ela implica. Em uma análise cuidadosa de cada caso específico, devemos esperar encontrar causalidade múltipla e algum grau de determinação estrutural, ao invés de apenas a vontade de uma única ação antiliberal. Dos exemplos listados acima, aproximadamente metade representa casos de invasão a partir de cima (do Estado), e a outra metade, de usurpação a partir de baixo (sociedade antiliberal). De uma forma geral, é de se esperar alguma interação entre essas duas fontes de constrangimentos.

Também devemos destacar um conjunto de ameaças não intencionais e não políticas. Estas têm natureza "estrutural" e, embora sejam amplamente conhecidas, merecem ser citadas: desemprego (que dificilmente conduz à civilidade ou à deliberação coletiva); criminalidade (que erode a autonomia dual e encoraja a usurpação); sistemas monopolistas de controle social local (que, independentemente de intenção política, bloqueiam a deliberação, estimulam a intolerância, obscurecem a legitimidade dos pontos de vista alternativos); os efeitos atomizantes da supremacia de mercado, e daí por diante. Novamente 0 propósito da lista não é amalgamar todas essas estruturas em uma ameaça indiferenciada, nem supor que elas sejam determinadas separada ou conjuntamente. Ao contrário, 0 objetivo é demonstrar a sua heterogeneidade e fragmentação. Isso implica que a sociedade civil sempre será pressionada a partir de múltiplas fontes, e que em qualquer comunidade política moderna 0 mais provável é que ela conviva com fontes persistentes e substanciais de incivilidade. Não haverá nunca a tendência à uniformidade de cobertura através de qualquer Estado nacional. Conseqüentemente, uma certa capacidade de organização sempre será requerida para a autodefesa e a auto-reprodução, de forma a que se consiga segurança e preservação da hegemonia política.

Em uma democracia moderna, esses bolsões ou estratos de incivilidade também possuem direitos políticos e têm sua parcela de representação na realização das políticas públicas. Dependendo, portanto, do seu tamanho e da sua capacidade de articulação política, eles ajudarão a conduzir a sociedade no rumo do governo demo- crático. Eles podem, na verdade, dar forma a regras e afetar a alocação de recursos que dão base à parte civil da sociedade. Por exemplo, se observamos a "deliberação autônoma" como um dos mais essenciais ingredientes de uma sociedade civil robusta, a democracia política pode perfeitamente dar poder a forças políticas que não têm interesse em promover tais práticas, mas, ao contrário, que as vêem como inúteis ou mesmo perigosas. De maneira similar, não pode haver garantia de que as maiorias eleitorais sempre favorecerão a preservação da "civilidade" tão cara às minorias mais bem instruídas. Ao contrário, a "autonomia e a civilidade" de uma parte podem ser facilmente interpretadas por outras partes da sociedade como privilégio elitista que precisa ser retirado.

A recente recondução ao poder, via eleições competitivas, de alguns dos partidos comunistas menos reformados nas novas democracias de vários países do Leste Europeu serve para ilustrar essa tensão persistente entre as reivindicações rivais de lealdade à sociedade civil e à democracia política. Todos os teóricos liberais eminentes, como Gray e Gellner, invocam visões da sociedade civil em contraposição ao comunismo, o que pode ser lido como a deslegitimação de tais resultados eleitorais. ${ }^{13}$

De maneira similar, Schmitter também reconhece a separação dos dois processos e 0 potencial de atrito entre eles, embora, em uma análise centrada na democracia capitalista, ele tenda a apresentar a sociedade civil como positiva para a consolidação democrática no longo prazo e em condições normais. A "sociedade civil, entretanto, não é uma dádiva completa para a democracia. Ela pode afetar a consolidação e 0 subseqüente funcionamento da democracia em uma série de formas negativas". Dentre essas ele inclui:

(2) A sociedade civil pode levar a uma distribuição da influência sistematicamente tendenciosa no processo de produção das políticas públicas;

(3) Ela tende a impor um acordo complexo e obscuro sobre a vida política, o que pode resultar em políticas públicas que ninguém queria desde 0 início e com as quais, conseqüentemente, ninguém pode se identificar; 
(5) Ainda mais perigoso, a sociedade civil "pode se revelar não uma, mas várias sociedades civis - todas ocupando o mesmo território e a mesma comunidade política, mas organizando interesses e paixões em comunidades que são distintas, ou até mesmo mutuamente exclusivas, étnica, lingüística e culturalmente". ${ }^{14}$

Os dois últimos parágrafos apresentaram imagens normativas diametralmente opostas da relação entre sociedade civil e democracia. No primeiro, a sociedade civil é o sustentáculo da liberdade, mas é ameaçada pela aplicação mecânica da política majoritária em uma sociedade com uma herança incivil ainda predominante. No segundo, a consolidação da democracia política é tomada como um objetivo desejável, e a sociedade civil pode, conseqüentemente, ser analisada e avaliada de acordo com a qualidade de sua contribuição potencial, que pode ser negativa. Segundo a primeira visão, quanto mais forte for a sociedade civil, melhor, mesmo que inerentemente esta seja mais "densa" em alguns locais do que em outros. De acordo com a segunda visão, somente as formas de sociedade civil que contribuem para a consolidação de uma alta qualidade de democracia política são claramente desejáveis. Outras formas também podem ser não igualitárias demais, excessivamente promotoras de pressões e desordens, ou mesmo muito "incivis" para serem desejáveis. $\mathrm{Na}$ verdade, democratização sólida pode necessitar de reformas amplas, e talvez até do enfraquecimento de sistemas herdados de vida associativa densa. ${ }^{15}$

A primeira versão sobre a relação entre sociedade civil e democracia parte do princípio da existência de um Estado que impõe idéias e conceitos. A sociedade civil então precisa se fortalecer contra essa fonte de ameaça à sua "autonomia dual". Na segunda perspectiva, diferentemente, assume-se implicitamente que falta autoridade ao Estado. 0 principal risco à autonomia dual, portanto, vem da captura da sociedade civil por interesses particularistas.

Como essas duas possibilidades são tanto teórica como empiricamente plausíveis, podemos concluir que a relevância moral que podemos dar à sociedade civil é indeterminada (talvez até "contestada essencialmente") nesse nível de abstração. Uma avaliação razoável dependerá, em parte, de onde o observador está localizado na estrutura social, e da forma pela qual uma sociedade civil particular funciona e se relaciona com o sistema político mais amplo. Talvez fosse melhor para a democracia norte-americana se todos fôssemos juntos a clubes de boliche mais freqüentemente. Mas enquanto no Upper East Side da ilha de Manhattan uma questão natural de deliberação para a comunidade seria a carga fiscal excessiva e o gasto social inútil, no Bronx uma forma diferente de civilidade poderia emergir com maior probabilidade. Da mesma forma, os impedimentos à ação coletiva efetiva quase certamente se mostrariam muito diferentes nos dois casos.

Uma forma de dar conta dessa diversidade é afirmar que quaisquer deliberações coletivas que não sejam subversivas, e que não infrinjam a lei, são tão legítimas quanto quaisquer outras. É claro, para atingir resultados positivos dentro de um quadro constitucional liberal seria necessário vencer vários interesses diversos. Algumas formas de deliberação conseqüentemente seriam mais bem-sucedidas do que outras (por serem mais persuasivas, ou orientadas de forma mais habilidosa). Mas formas não efetivas e não persuasivas de deliberação também são permitidas, desde que não infrinjam um pequeno número de proibições definidas claramente. Em princípio, na verdade, esse é o caminho pelo qual os regimes democráticos definem 0 âmbito das deliberações toleráveis. Mas será que o mesmo critério serve para limitar o escopo do debate no interior da sociedade civil? De acordo com a definição adotada aqui, a resposta a essa pergunta é aparentemente não.

$\mathrm{Na}$ maioria das definições (incluindo a usada aqui), seria mais plausível dizer que algumas formas de discussão que não são ilegais em uma democracia podem ser, entretanto, incivis, ou ameaçadoras das normas cruciais de não usurpação e tolerância interpessoal. Várias formas de fundamentalismo religioso podem ter de ser toleradas no interior de uma democracia, mas não podem ser consideradas como parte de uma "so- 
ciedade civil" liberal moderna. Uma família rica pode se empenhar em comprar um jornal e utilizá-lo para desacreditar seus inimigos, e pode executar toda a operação tomando cuidado para permanecer o tempo todo dentro da lei, mas isso não envolve nenhuma manifestação de autonomia dual ou de civilidade. Administradores públicos podem criar um conluio para reter informações que o eleitorado "deveria" saber (de forma a poder fazer escolhas políticas bem fundadas), e novamente isso pode ser feito dentro da lei, mas mesmo assim é "incivil". Na verdade, a própria questão de quão rigorosamente a lei será cumprida em várias situações pode também ser objeto de manipulação incivil que permaneça dentro dos limites das ações permitidas constitucionalmente.

Resumindo, no domínio do discurso coletivo, assim como no reino da estrutura social, há um vazio entre a cobertura estreita do que pertence propriamente às várias concepções de "sociedade civil" e a cobertura ampla requerida de uma comunidade política. De um lado desse vazio podemos identificar deliberações "incivis" e estratos sociais "incivis". A fronteira precisa entre 0 civil e 0 incivil pode ser difícil de definir mesmo em princípio, e mais ainda na prática. Podese esperar que alianças de conveniência sejam construídas de tempos em tempos cobrindo 0 vazio (como quando os barões da mídia incivis se associam às mais respeitáveis instituições liberais na defesa de algum assunto de interesse comum, ou quando fundamentalistas procuram a proteção de forças políticas libertárias civis). Mas, se a "sociedade civil" carrega quaisquer das conotações morais e sociológicas consignadas a ela pelos teóricos, deve haver uma fronteira delimitável. Se assim for, as atividades que repousam do outro lado dessa fronteira - no campo que denominei de "interstícios incivis entre a sociedade civil e a sociedade política" - podem ser de grande significância para a qualidade e a estabilidade da democracia como um todo. Esta seção tenta ilustrar a extensão desses efeitos mesmo em democracias ocidentais bem estabelecidas. Sendo assim, pode-se argumentar que em democracias novas esses interstícios incivis ocupam um espa- ço social freqüentemente muito maior do que 0 ocupado pela própria sociedade civil emergente. ${ }^{16}$ Para analisar 0 escopo da "consolidação democrática" nessas sociedades, necessitamos, portanto, prestar atenção às manifestações políticas da "sociedade incivil" nas democracias emergentes. Também precisamos considerar como a escala e 0 poder dessa sociedade "incivil" podem afetar o conteúdo e as características de qualquer forma de sociedade civil correspondente. A seção final deste artigo destaca algumas idéias preliminares a esse respeito.

\section{A sociedade civil e o "Outro"}

Se a sociedade civil se caracteriza por sua capacidade de deliberação e pela ação coletiva (nos limites estabelecidos pela não usurpação e pela civilidade), então podemos esperar que ela delibere e aja sobre as ameaças previsíveis à sua existência, ou à sua capacidade de desenvolvimento futuro. Essas ameaças podem ser atribuídas primariamente à "sociedade tradicional" e a seus constrangimentos habituais, ou ao "Estado moderno", com suas propensões à racionalização e à atomização. Entretanto, particularmente em democracias recentes, elas podem também estar localizadas nos interstícios incivis da nova comunidade política (nem no privado-tradicional nem no público-burocrático).

Cada um desses diagnósticos invoca um modelo (ou teoria) alternativo e implica uma estratégia particular de autoperpetuação. Em qualquer exemplo particular, essas três concepções rivais podem ser encontradas em conflito no interior das assembléias de uma dada "sociedade civil". Quando a família tradicional e as lealdades particularistas são definidas como o problema central a ser superado, estratégias de "fortalecimento do Estado" podem parecer aceitáveis, particularmente aquelas que fortalecem a "esfera pública" pela garantia de direitos cívicos impessoais e reforçando 0 Estado de direito. Mas quando (como nas democracias recentes pós-comunistas, e também no discurso neoliberal latino-americano) a realização de inúmeras tarefas pelo Estado é vista como uma ameaça, então a desregulamentação, a priva- 
tização e a redução do Estado tornam-se as estraté gias preferidas. Em princípio, estes também podem envolver 0 aprimoramento de alguma forma de "espaço público" onde os agentes autônomos possam interagir sem manipulação. Nesse caso, também pode-se sustentar que a legalidade imparcial e os direitos estão presentes, mas faz uma grande diferença que esses direitos sejam assegurados contra o Estado, ao invés de sob a sua proteção, e que o sistema judicial seja submetido à mesma austeridade e aos mesmos testes de mercado que 0 resto da burocracia estatal. ${ }^{17}$ Isso porque, nessas condições, o Estado de direito resultante responderá acima de tudo aos requerimentos do comércio, ao invés de se submeter à racionalidade dirigida do Estado. ${ }^{18} \mathrm{Na}$ linguagem de Habermas, isso leva ao empobrecimento cultural e à colonização do mundo-da-vida, a partir do qual se supõe que a sociedade civil moderna deva emergir.

Como a norma da "autonomia dual" deixa claro, as sociedades civis estão sempre, de alguma forma, sob pressão de ambos os lados, do particularismo tradicional e do Estado que se intromete excessivamente. A preservação e 0 aumento de uma esfera autônoma requerem um fluxo constante de recursos e de novos membros, regulados com vigilância e continuidade de propósitos. A sociedade civil consiste em centros de associação múltiplos que se autoperpetuam, competindo tanto quanto cooperando a fim de promoverem interesses rivais e projetarem suas concepções alternativas de autonomia, civilidade e autopreservação. Alguns desses centros encolherão graças ao particularismo, mas esperam se beneficiar da força do ativismo estatal. Outros resistirão firmemente ao direcionamento imposto pelo Estado, mas aceitarão se aliar a aspectos do tradicionalismo social. No interior de cada sociedade civil, perspectivas e prioridades alternativas competirão por ascendência com sucesso flutuante à medida que se perceba que 0 ambiente externo muda.

Mas, e se, como em muitas democracias recentes, o maior risco para a sociedade civil não vier - ou ao menos se considerar que não venha - nem do estatismo, nem do particularismo tradicional, mas de uma incivilidade majoritária de moldes modernos? A referência aqui diz res- peito a fenômenos como a irresponsabilidade impessoal da mídia de massa comercializada moderna; a impulsividade de um eleitorado desorientado e desenraizado; a visão de curto prazo dos mercados financeiros especulativos; a insegurança gerada pelo crime bem organizado, tipicamente localizado em setores estratégicos como 0 tráfico de armas, a lavagem de dinheiro e 0 comércio de narcóticos? As normas da autonomia dual, da deliberação racional, da civilidade e dos "direitos fundamentais universais" de Cohen e Arato podem todas ser sitiadas por incivilidades potencialmente majoritárias como essas, o que não pode, na sua maior parte, ser atribuído diretamente a nenhuma das duas fontes típicas de ameaça contra a sociedade civil. Como já tive oportunidade de destacar, essa terceira forma de desafio à sociedade civil agora pode ser encontrada em todos os lugares - mesmo nas democracias liberais mais seguras e mais desenvolvidas. Alguns teóricos enfatizam como novas tendências dominantes a importância da integração global e a erosão da autonomia do Estado-nação. $\mathrm{Na}$ minha opinião, isso pode ajudar a explicar alguns dos elementos de incivilidade majoritária listados acima, mas de forma alguma todos. Particularmente em democracias recentes, com freqüência a maneira pela qual os regimes autoritários acabaram e as heranças incivis que eles deixaram para trás com 0 seu final apresentam-se como mais críticos do que a erosão do Estado nacional como tal.

Nas democracias recentes, as sociedades civis emergentes são, por definição, incipientes e ainda não testadas. As normas da autonomia dual, da deliberação independente e da civilidade foram pouco cultivadas durante 0 domínio autoritário (exceto, talvez, entre algumas minorias muito privilegiadas sob o regime que Linz denominou de "pluralismo limitado") e, conseqüentemente, elas tiveram de ser promovidas e mantidas frente à frente com a opressão oficial. Isso trouxe uma intensa experiência de aprendizado às minorias de ativistas, e com frequência a sua influência social explodiu quando 0 regime autoritário deixou 0 poder. Na melhor das hipóteses, entretanto, eles eram um grupo selecionado e nem todos dentre 
eles eram profundamente socializados nas normas da civilidade. Assim, as escolhas que eles enfrentaram durante 0 período confuso da democratização os dispersaram em atividades amplamente espalhadas. (A virtual desintegração do bloco Solidariedade na Polônia depois de 1989 parece ser um caso paradigmático.) Vários grupos ativos educados em normas menos civis estiveram competindo com eles por influência na vida pública depois da transição - pragmáticos da estrutura de poder autoritária; revanchistas, chauvinistas e fundamentalistas, de outros setores da oposição; os novos ricos, freqüentemente preocupados com a "acumulação primitiva"; consultores estrangeiros do tipo "vendedores de tapetes", sem nenhum compromisso durável com a sociedade local, e daí por diante. A lista poderia ser estendida mais ainda, mas 0 ponto já está claro. Nessas situações, qualquer sociedade civil que tenha sido estabelecida de forma precária será frágil e estará sitiada de todos os lados. Ela terá de dar conta de uma comunidade política povoada, em sua maioria, por atores cujo compromisso com a civilidade é questionável ou ausente.

Muito tempo antes de essa "sociedade civil" ter sido estabilizada e consolidada, a comunidade política terá produzido uma sucessão de decisões fundadoras que constrangerão fortemente os padrões de interação política. Não há dúvida de que certas formas de engenharia constitucional podem melhorar as perspectivas de uma sociedade civil viável (por exemplo, através de uma lei de direitos bem elaborada, ou talvez através do parlamentarismo ou do federalismo). De maneira similar, algumas estratégias de modernização econômica têm maior probabilidade de encontrarem apoio do que outras (por exemplo, esquemas de regionalismo aberto baseados em leis, desregulamentação, algumas formas de privatização). Mas não há nenhuma receita única e garantida aplicável em todos os casos, nem a saúde da sociedade civil deve ser 0 único ponto para consideração quando as alternativas são submetidas à escolha. $\mathrm{Na}$ prática, outras considerações normalmente mostrar-se-ão decisivas. Não há tampouco uma única forma pela qual os líderes de uma sociedade civil incipiente devam responder necessaria- mente às contradições internas e aos constrangimentos externos que eles enfrentam, mas o conjunto de alternativas compatível com a sobrevivência e eventual crescimento é certamente limitado e inibidor da ação. Em alguns casos, sociedades civis fortes podem, apesar de tudo, ser construídas ao longo de um período de tempo significativo, mas não sob condições de sua própria escolha. Utilizando a linguagem de Gellner, as condições para uma sociedade civil realista podem não permitir a realização da sociedade civil ideal.

A existência de governos constitucionais baseados no sufrágio universal normalmente implica que aqueles que querem realizar um ideal de conduta pública devem promover a sua causa através da política partidária ou ao menos através do processo eleitoral. Entretanto, as normas da "autonomia dual" e da "não usurpação" que atribuímos à sociedade civil implicam que o termo não deve ser estendido para incluir as organizações políticas que competem para ocupar cargos públicos. Além disso, em muitas democracias recentes, algumas das organizações mais eficientes em vencer eleições se ressentem de uma tradição de compromisso com a norma de "civilidade" e/ ou permitem muito pouca "deliberação" em seus assuntos internos. Portanto, geralmente não há nenhuma razão particular para esperar uma "afinidade eletiva" entre uma sociedade civil vigorosa e a presença de partidos políticos bem-sucedidos eleitoralmente. Decerto, em vários casos podemos verificar que a emergência de uma sociedade civil com base mais ampla é seguida pelo estabelecimento de partidos políticos democráticos que agem de acordo com uma sociedade civil ideal. Mas outros dois modelos são igualmente plausíveis: (a) um antagonismo entre os arquitetos da sociedade civil e os líderes partidários bem-sucedidos ou (b) uma compartimentação das duas esferas. ${ }^{19}$ A relação entre sociedade civil e partidos políticos requer, claramente, análise cuidadosa, que não foi possível executar ao longo deste artigo ${ }^{20}$ Mas nós podemos aqui ao menos advertir contra 0 erro do reducionismo.

Mas e se o "Outro" contra o qual as cabeças pensantes da sociedade civil podem se organizar 
não for nem o Estado autoritário, nem a inércia da tradição, mas, ao contrário, a insegurança, a rudeza, a arbitrariedade e até mesmo 0 canibalismo social que tem sido associado a tantas sociedades liberalizadas após a transição? Que tipo de sociedade, baseada em quais princípios organizativos, pode sobreviver e se desenvolver diante desse "Outro" anômico moderno? Uma "cidade" hobbesiana, talvez unida apenas pelo medo da guerra de todos contra todos circundante? Guildas hegelianas? Ou uma burguesia marxista? Uma rede tocquevilliana de associações locais (e clubes de boliche)? Ou mesmo o "mundo-da-vida" da interação comunicativa de Habermas? Cada uma dessas respostas tende a privilegiar uma categoria sociológica particular - especialistas em segurança, mestres artesãos, capitalistas, jomalistas locais, intelligentsia, e daí por diante - e nenhuma delas parece aplicável, de forma autoevidente, às democracias recentes como um todo. Cada qual pode sugerir um fragmento de um todo potencial, mas nenhuma fornece um guia claro com relação aos princípios sob os quais elas deveriam ser integradas. $\mathrm{Na}$ prática, diferentes formas de sociedade civil provavelmente mostrar-se-ão relativamente viáveis em democracias recentes, mas de um modo geral podemos concluir que os princípios de integração mais eficazes virão mais provavelmente de fora do que de dentro. Isso quer dizer que as sociedades civis que obtenham melhores resultados com as pressões das maiorias incivis têm as melhores perspectivas. Se elas conseguirão ou não corresponder às esperanças idealistas que tantos teóricos recentes depositam nelas é um outro problema.

\section{NOTAS}

1 Para uma compilação útil e atualizada dessas complicações, incluindo a desagregação institucional e regional, e uma discussão dos julgamentos de Andreotti, cf. Violante (1996).

2 Le Monde, 30/12/1995, p. 5.

3 A Grã-Bretanha, como muitas das "poliarquias" estabelecidas há muito tempo, estende os direitos políticos (direitos de voto e de organização) a comunidades de tamanho significativo que rejeitam a sua autoridade constitucional e que consideram legítimo participar de formas "incivis" de oposição política. O Sínn Féin, o Heri Batasuna e os nacionalistas da Córsega ilustram esse padrão de incivilidade.

4 O título é também uma referência ao artigo de Putnam (no prelo). Putnam conclui que nos Estados Unidos "a participação caiu (com frequêencia de forma abrupta) em vários tipos de associações cívicas, de grupos religiosos a sindicatos de trabalhadores, de clubes de mulheres a clubes de fraternidades e do encontro de vizinhança a ligas de boliche. Virtualmente todos os segmentos da sociedade foram atingidos por essa redução no relacionamento social [...] [que] parece ser um provável determinante de vários dos males sociais e políticos que afligem no momento os Estados Unidos, e que talvez coloquem em cheque também outras democracias avançadas.

5 Para uma exposição recente e sofisticada conduzida a partir de dentro da tradição da teoria crítica alemã, cf. Cohen e Arato (1993). Dentre os muitos autores de primeira linha analisados por eles, Arendt, Gramsci, Parsons e inevitavelmente Habermas recebem atenção particularmente cuidadosa. Cf. cap. 9.

6 Note-se que essa definição inclui os sindicatos de trabalhadores mas exclui as empresas privadas. Onde ficam, então, as empresas de comunicação e mídia de propriedade privada, assim como as igrejas?

7 Gellner (1994, pp. 8 e 10). Quem considerar a linha de argumentação de Gellner excessivamente eurocêntrica pode utilizar Carrithers, Collins e Lukes (1985) e Godoy (1996) para a correção parcial de tais problemas.

8 Collingwood (1992, p. 292, parags. 35-41). No entanto, resta a pergunta: a norma de civilidade também se aplica ao tratamento dos grupos externos, aqueles não cobertos pelas regras preestabelecidas ou não socializados por essa concepção de auto-respeito? O livro de Collingwood foi publicado no momento mais grave da Segunda Guerra Mundial (janeiro de 1942) e parece um pouco ambivalente sobre essa questão crucial.

9 Na sua narrativa do que denomina "a transformação estrutural da esfera pública", Habermas vê a sociedade civil como a arena na qual a opinião pública pluralista consegue se fazer passar por fonte independente de poder. Entretanto, algumas vozes obviamente se expressam mais alto do que outras na arena da opinião pública, e nem todas as opiniões que se expressam em uma arena pública não restringida são igualmente "civis". Cf. Habermas (1993).

10 Para uma apresentação recente e vigorosa desse caso ver Hirst (1994).

11 Em uma visita recente à África do Sul, fiquei impressionado com a riqueza e estabilidade da sociedade civil que tinha servido de abrigo à população branca - e talvez mesmo à população de cor da Província do Cabo - sob o apartheid, ao mesmo tempo que as possibilidade pacíficas de associação da maioria não branca eram suprimidas ativa e energicamente. 0 Ulster protestante provavelmente também apresenta uma polariza- 
ção de alguma forma comparável na promoção da sociedade civil, nesse caso legitimada pelo sufrágio universal que garantiu a subordinação dos católicos.

12 Se os amigos de Putnam não jogam mais boliche, isso acontece, em parte, pela existência de tantas diversões competidoras que estão presentes eletronicamente e em casa nos dias de hoje.

13 No seu último livro, Ernest Gellner (1994, pp. 188-189) apresenta convincentemente os dois argumentos teóricos rivais que reivindicam validação, e afirma a sua escolha claramente: "Teóricos da democracia que operam no abstrato, sem referência às condições sociais concretas, acabam por absolver a democracia como uma idéia geral, mas são obrigados a conceder que em muitas sociedades 0 ideal não é realizável.[...] Não é melhor afirmar as condições que fazem a idéia viável, ou mesmo obrigatória, e começar a partir daí? A sociedade civil é uma noção mais realista, que especifica e inclui as suas próprias condições [...] Como destacam aquelas precondições institucionais e o contexto histórico necessário, a 'sociedade civil' é provavelmente um slogan mais esclarecedor do que democracia".

14 Schmitter (1995, p.14). Note-se que essas potencialidades negativas tendem a contrabalançar os atributos positivos enfatizados pela definição inicial de Schmitter. Aqui, a não usurpação torna-se desvirtuamento das políticas públicas, a deliberação torna-se opacidade e a civilidade torna-se tribalismo. É difícil sustentar uma imagem idealizada da sociedade civil que ao mesmo tempo dê conta do seu impacto desigual no funcionamento de uma comunidade política mais ampla.

15 Carlos M. Vilas (1996) apresenta algumas ilustrações impressionantes desse ponto de vista em um panorama geral das novas democracias na América Central. Ele retrata as oligarquias locais fundadas na herança direta das estruturas de exclusividade social que aprenderam a desfilar a retórica da democracia de mercado como discurso público, mascarando a continuidade de sua supremacia, enquanto suas práticas sociais mais íntimas perpetuam valores altamente antidemocráticos. Comparar com Gyimah-Boadi (1996) sobre as fraquezas da sociedade civil na África: os "valores pré-liberais e antiliberais [...] tendem também a impregnar as associações civis seculares e modernas [...] tendências a que algumas associações civis-chave se recusem a estabelecer burocracias 'racionais'; a 'ungir' ao invés de eleger os seus executivos (incluindo aqueles envolvidos no trabalho pró-democracia); e a dotar seus líderes de mandatos vitalícios".

16 Giorgio Alberti (1995), da Universidade de Bolonha, baseou seu conceito de movimentismo no Peru e na Argentina em um argumento análogo. Guillermo O’Donnell (1993) cunhou o termo "áreas marrons" para se referir a amplos setores da sociedade latino-americana onde condições incivis prevalecem.

17 Comparar o debate checo sobre a "sociedade civil", em que 0 presidente Havel tenta promover o conceito como um corretivo para a ênfase excessiva na relações puras de mercado, enquanto o primeiro-ministro Havel iguala democracia com liberdade individual, incluindo liberdade da engenharia social em nome da sociedade civil. Cf. Havel, Klaus e Pithart (1996).

18 Lembremos do pluralismo liberal de Durkheim, para quem era o Estado quem "criava e organizava e fazia dos direitos naturais individuais uma realidade". $\mathrm{Na}$ verdade, a sua "função essencial" era "liberar as personalidades individuais", contrabalançando a pressão sobre elas dos grupos domésticos locais, eclesiásticos, ocupacionais e demais grupamentos secundários (enquanto os últimos também precisavam contrabalançar a tirania potencial do Estado). Cf. Lukes (1973).

19 Essas três alternativas foram elaboradas por Forment (1995).

20 Minha abordagem tem sido excluir todos os partidos políticos da "sociedade civil", baseado no fato de que eles competem por cargos nacionais. Uma alternativa a isso seria incluir os partidos políticos que representem os interesses de setores substanciais da sociedade civil (e somente esses). Isso envolveria fazer algumas distinções discricionárias entre partidos políticos. O Partido Comunista Italiano expressa os interesses de elementos de destaque na sociedade civil, ou ele os substitui e os subordina a seus interesses? Isso é estável ao longo do tempo, ou variável? Como podemos provar uma interpretação ao invés da outra?

\section{BIBLIOGRAFIA}

ALBERTI, Giorgio. (1995), "Movimentismo" and democracy: an analytical framework and the Peruvian case study. Bolonha, CESDE, mimeo.

CARRITHERS, Michael, COLLINS, Steven e LUKES, Steven (orgs.). (1985), The category of the person: A nthropology, Philosophy and H istory. Cambridge, Cambridge University Press.

COHEN, Jean e ARATO, Andrew. (1993), Civil society and political theory. Cambridge, MIT Press.

COLLINGWO OD, R.G. (1992), The new L eviathan: on man, society, civilization and barbarism. Oxford, Clarendon Press.

FORMENT, Carlos A. (1995), Civil society and the invention of democracy in nineteenth century Cuba. Princeton, Princeton University, mimeo.

FUKUYAMA, Francis. (1995), Trust: new foundations of global prosperity. Londres, Hamish Hamilton.

GELLNER, Ernest. (1994), Conditions of liberty: civil society and its rivals. Londres, Allen Lane.

GOODY, Jack. (1996), The E ast in the W est. Cambridge, Cambridge University Press. 
GYIMAH-BOADI, E. (1996), "Civil society in Africa". Journal of Democracy, $7,2$.

HABERMAS, Jürgen. (1993), Strukturwandel der Öffentlichk eit. Frankfurt, Suhrkamp.

HAVEL, Vaclav, KLAUS, Vaclav e PITHART, Petr. (1996), "Rival visions". Journal of D emocracy, 7, 1.

HEGEL, Friedrich G. W. (1942), H egel's philosophy of rights. Oxford.

HIRST, Paul. (1994), A ssociative democracy: new forms of economic and social governanoe. Massachusetts, University of Massachusetts Press.

HOBBES, Thomas. (1651), Philosophicall rudiments concerning government and society.

LUKES, Stephen. (1973), E mile D urkheim. Londres, Allen Lane.

O’D O NNELL, Guillermo. (1993), "On the State, democratization and some conceptual problems: a Latin American view with glances at some postcommunist countries". W orld D evelopment, 21, 8.

PUTNAM, Robert. (1994), Making democracy work: civic traditions in modern Italy. Princeton, Princeton University Press.

(no prelo), "Bowling alone: democracy in America at the end of the twentieth century", in D. Ruechemeyer (ed.), Participation and democracy: E ast and W est.

SCHMITTER, Philippe. (1995), On civil society and the consolidation of democracy: ten propositions. Stanford, Departament of Political Science, mimeo.

TOCQUEVILLE, Alexis. (1945), D emocracy in A meric. Nova York, Alfred Knopf.

VILAS, Carlos M. (1996), "Prospects for democratization in a post-revolutionary setting: Central America". Journal of Latin A merican Studies, 28, parte 2 .

VIOLANTE, Luciano (org.). (1996), Mafie e antimafia: rapporto '96. Roma, Laterza. 